\title{
Informing Students Using Virtual Microscopes and Their Impact on Students' Approach to Learning
}

\author{
Diana Jonas-Dwyer and Fay Sudweeks \\ University of Western Australia and Murdoch University \\ Perth, Australia
}

diana.jonas-dwyer@uwa.edu.au sudweeks@murdoch.edu.au

\begin{abstract}
This research is an exploratory study of students' approaches to studying histology and pathology. With the introduction of virtual microscopes in Health Science at Murdoch University, Australia, in 2006, it was crucial to investigate how this new technology impacted on students' approaches to learning. The ASSIST survey was implemented at the beginning and end of the semester to identify any changes. Results indicate that, when the technology was integrated into the curriculum with appropriate learning activities, students using virtual microscopes moved more towards a strategic approach to learning but expressed a preference for a deep approach to teaching.
\end{abstract}

Keywords: virtual microscopes, histology, study approaches, deep learning, e-learning.

\section{Introduction}

Increasing student numbers and decreasing resources in universities are placing greater pressures on faculty to find efficient and effective ways to teach their subject specialties. In the fields of veterinary and health sciences, increases in student numbers and technological advances in computer hardware and software since the 1990s have led to increased use of computers and technology for teaching and learning (Ryan, Irwin, Bannon, Mulholland, \& Baird, 2004). As with other disciplines, the use of technologies such as learning management systems (e.g. WebCT) and streamed audio (e.g. iLecture) are means by which faculty can more efficiently and effectively teach.

A technology being increasingly adopted in veterinary science and medicine is virtual microscopes. Virtual microscopes were introduced into the teaching of histology and pathology at the University of Iowa (USA) in 2000 (Harris et al., 2001) and at Leeds University (UK) in 2005. A virtual microscope is defined as "hardware, for slide digitisation and software viewers that allow users to zoom and change magnification to examine digitised slides" (Aperio Technologies, 2006). A virtual microscope is not to be confused with an electronic simulation of a microscope,

Material published as part of this publication, either on-line or in print, is copyrighted by the Informing Science Institute. Permission to make digital or paper copy of part or all of these works for personal or classroom use is granted without fee provided that the copies are not made or distributed for profit or commercial advantage AND that copies 1) bear this notice in full and 2) give the full citation on the first page. It is permissible to abstract these works so long as credit is given. To copy in all other cases or to republish or to post on a server or to redistribute to lists requires specific permission and payment of a fee. Contact Publisher@InformingScience.org to request redistribution permission. which is a complete model of an optical microscope and slides.

Educational researchers investigating the effects of technology use on learning have reported contradictory results. Some are sceptical of the impact on learners. Russell (1999, p.xiii), for example, states that "There is nothing inherent in the technology that elicits improvements in learning" although the 
process of redesigning a course to adapt content to the technology can have the effect of improving the outcomes. Some believe that the technology has been driving the teaching instead of the teaching driving the technology (Bates \& Poole, 2003), but others are more positive and say, for example, that "E-learning will inevitably transform all forms of education and learning in the twenty-first century" (Garrison \& Anderson, 2003).

Research into student learning (e.g. Biggs, 2003; McCune \& Entwistle, 2000) has found that students' learning is influenced by many factors, e.g. individual student characteristics, the learning environment and the teachers' teaching styles. Some student characteristics are considered to be "fixed", e.g. students' cognitive styles, whilst other characteristics are more "adaptable", e.g. students' learning approaches.

Approaches to studying identify more than just students' intrinsic characteristics; they also exist as functions of the learning environment. Students adopt varying approaches to studying based on personal factors (e.g. preferred study approach) and teaching context (e.g. the learning environment provided). Biggs (2003) has identified three different approaches to studying: (i) deep approaches are characterised by a preference to work conceptually and are driven by intrinsic curiosity; (ii) strategic approaches are characterised by a focus on obtaining high marks and organised studying; and (iii) surface approaches are characterised by an intention to achieve a pass, avoid too high a workload, misunderstanding requirements, and/or thinking that factual recall is all that is required.

Research into students' approaches to learning is abundant. There are many instruments available to measure students' approaches to studying and others to measure students' learning styles. A recent report on learning styles and pedagogy (Coffield, Moseley, Hall, \& Ecclestone, 2004) examined 13 of the most influential models and concluded that "it matters fundamentally which instrument is chosen" by researchers. They recommended Allison and Hayes Cognitive Style Index instrument as they felt it had the best evidence for reliability and validity of all the models examined, even though the pedagogical implications of the model had not been fully explored.

However, three of the most commonly used instruments for student learning approaches are the Study Process Questionnaire (SPQ) (Biggs, 1987), the Inventory of Learning Styles (ILS) (Vermunt, 1988), and the Approaches and Study Skills Inventory for Students (ASSIST) (Entwistle, 2000). The ASSIST was previously known as the Approaches to Study Inventory (ASI) but developed over time to be Revised Approaches to Study Inventory (RASI) and then the ASSIST. The instrument is being continually refined and improved (Entwistle, 2006, personal correspondence).

Biggs (2003, p.29) suggests that "constructive alignment" be used to encourage deep learning in undergraduate teaching environments. Constructive alignment is characterised when curriculum objectives, teaching/learning activities and assessment tasks are aligned. McCune and Hounsell (2005) elaborate further and suggest that "any such environment is a complex composite of many interacting influences that need to be aligned towards supporting deep active learning, if there is to be any overall effect".

As the use of virtual microscopes for teaching histology to Health Science students is a relatively new development, there is limited research on the resulting impact on students' approaches to learning. The research to date has mainly concentrated within the field of medicine in histology and pathology. Harris et al. (2001) compared virtual and regular (optical) microscope laboratory classes for teaching histology to medical students and found virtual microscopic labs were a viable addition, if not a replacement for, real microscopes and glass slides. Students gave higher ratings to the accessibility and efficiency of the virtual microscopes and to the quality of the images and navigation in comparison to the regular microscopes. The use of virtual microscopes also provides more opportunities for teachers to use strategies that promote self-directed and in- 
dependent student group learning as well as providing more flexible access to virtual microscopes outside of regular labs.

There are increasing pressures on academics to incorporate economically efficient, as well as effective, means to teach their subject specialties. The increased use of technologies, prime facie, appears to be the solution. However, as yet there is not sufficient knowledge about the impact of such technologies, particularly on students' different learning approaches.

Given the paucity of research on the relationship between the use of virtual microscopes and deep learning, this paper is an exploration of the critical factors for ensuring effective student learning with the introduction of such new technologies.

\section{Methodology}

The research involved a descriptive study of third year chiropractic students' self-perceptions while studying histology and pathology as part of an undergraduate degree in Chiropractic. Thirdyear Chiropractic students were randomly allocated to either a traditional optical microscopy group or a virtual microscopy group for their laboratory classes. Group A used optical microscopes and Group B used virtual microscopes. All students had previous experience with using optical microscopes. Laboratory sessions involved viewing histology or pathology slide specimens with a microscope to review lecture content for the week, e.g. structure and function of normal or abnormal tissue.

\section{Participants}

The target population was 57 third-year Chiropractic students studying histopathology. Of the 57 available students, 47 consented to take part in the study.

\section{Materials}

The Approaches and Study Skills Inventory for Students (ASSIST) (Entwistle, Tait, \& McCune, 2000) was used to identify students' preferred approaches to studying. Students completed a demographic survey and an ASSIST survey at the beginning of the semester and another ASSIST survey at the end of the semester.

Students also kept log books of the hours they spent studying, including lecture attendance, laboratory class attendance where microscopes were used, and self-study. The log book, in Microsoft Excel format, was provided to students to keep a track of their activities.

\section{Procedure}

Students attended a presentation by one of the researchers at their first laboratory class explaining the study, informing them of ethics approval for the study and aims of the research, and describing what being a participant in the study entailed. The students were asked give their consent to be part of the study and were also informed that they could withdraw from the study at any time without prejudice. The first ASSIST survey was completed in the first laboratory class and the second ASSIST survey was completed in the last laboratory class. The surveys were collected by one of the researchers. The log books were submitted online to one of the researchers via WebCT.

\section{Results}

Although 47 of the possible 57 students consented to be in the study, only students who completed both ASSIST surveys were included, thus data from 35 students were analysed. The 35 students were comprised of 19 students in Group A (optical) and 16 students in Group B (virtual). 
Informing Students Using Virtual Microscopes

The log books recording students' time spent studying and the frequency of their study were analysed by calculating the total reported time spent studying for each student.

\section{Demographics}

Students provided information about age, gender, and previous level of education undertaken prior to commencing their current degree. There were approximately twice as many females $(65 \%)$ as males $(38 \%)$ who completed all of the requirements to be included in the study. This imbalance was not representative of the gender distribution of the whole class, which was almost equal. The age range of the two groups was between 19 and 45 years, with the majority of students falling into the 20-24 year age group (Table 1).

Table 1: Students' Age by Group.

\begin{tabular}{|c|c|c|}
\hline Age (at time of survey) & Group A (Optical) & Group B (Virtual) \\
\hline 19 & $11 \%$ & $19 \%$ \\
\hline $20-24$ & $44 \%$ & $68 \%$ \\
\hline $25-29$ & $11 \%$ & $13 \%$ \\
\hline $30-34$ & $17 \%$ & $0 \%$ \\
\hline $35-39$ & $11 \%$ & $0 \%$ \\
\hline $40+$ & $6 \%$ & $0 \%$ \\
\hline
\end{tabular}

Students also rated their skills with the Internet and computers using a 5-point Likert scale with 1 representing 'very skilled' and 5 representing 'little or no skills'. Figure 1 shows that the majority of students in both groups $(63 \%)$ rated themselves as possessing a medium level of skills, while a small proportion $(5 \%)$ of the optical group rated themselves as being very skilled and a small proportion $(6 \%)$ of the virtual group rated themselves as having less skills. Neither group rated themselves with little or no skills.

\section{Approaches to Studying}

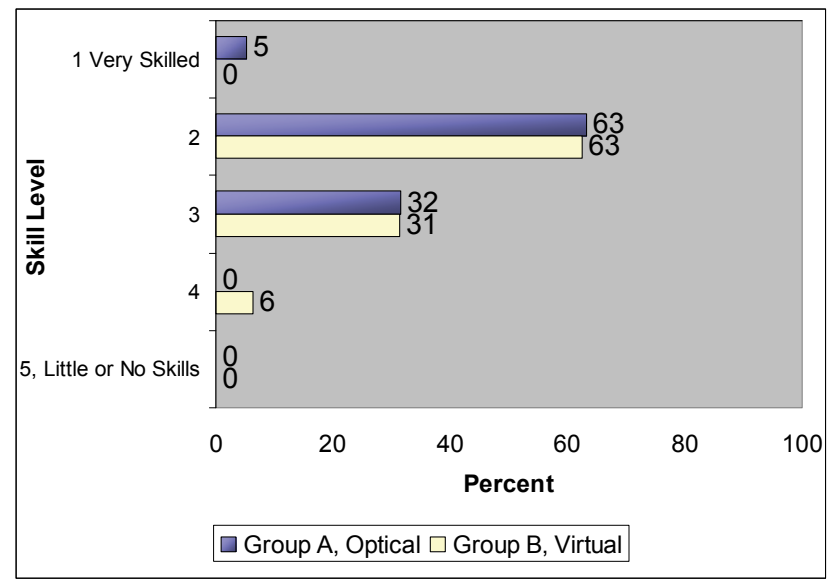

Figure 1: Students self-rating of ICT skills.

The ASSIST survey was given to students twice, once at the beginning of semester (now referred to as ASSIST1), and again at the end of semester (now referred to as ASSIST2). The ASSIST survey comprises three sections. Section 1 of the survey identifies students' conceptions of learning. Section 2 identifies students' preferred approach to studying as deep, strategic or surface. A deep approach comprises four subscales: seeking meaning; relating ideas; use of evidence; and interest in ideas. A strategic approach comprises five subscales: organised studying; time management; alertness to assessment demands; achieving effectiveness; and monitoring effectiveness. A surface approach comprises of four sub-scales: lack of purpose; unrelated memorising; syllabus-boundness; and fear of failure. Section 3 identifies students' preferences for different types of course and teaching. In addition to these three sections, there is a final question about students' perceptions of how well they have been doing in their assessed work overall. Each segment of the survey will be discussed in the following sections. 


\section{Section A of the ASSIST - Student conceptions of learning}

Students completed the first ASSIST survey in the first laboratory session. Section A of the ASSIST identifies students' conceptions about learning. Students' conceptions about learning show whether they see learning as being about personal understanding and development or whether they see learning as reproducing knowledge. Where the scores for both conceptions are equal they are not placed into either category.

Table 2 shows the results of Section A of both ASSIST surveys for Group A (optical). In ASSIST1, almost half of the students $(42 \%)$ indicated their view of learning involved personal understanding and development and almost a quarter (21\%) indicated their view of learning as reproducing knowledge. In ASSIST2, there was a decrease in the number of students selecting personal understanding and development $(26 \%)$ and a slight increase in those selecting learning as reproducing knowledge (32\%).

Table 2: Section A (Comparison of Students' Conceptions of Learning) of the ASSIST Survey for Group A (optical) in ASSIST1 and ASSIST2.

\begin{tabular}{|l|l|l|}
\hline Conceptions of Learning for Group A & ASSIST1 & ASSIST2 \\
\hline Personal understanding and development & $42 \%$ & $26 \%$ \\
\hline Equal & $37 \%$ & $42 \%$ \\
\hline Reproducing knowledge & $21 \%$ & $32 \%$ \\
\hline
\end{tabular}

Table 3 shows the results of Section A of both ASSIST surveys for Group B (virtual). In ASSIST1, almost half of the students (44\%) indicated their view of learning involved personal understanding and development and a quarter (25\%) indicated their view of learning as reproducing knowledge. In ASSIST2, there was a substantial increase in the number of students selecting personal understanding and development $(69 \%)$ and no change in those selecting learning as reproducing knowledge (25\%). The different results across the two surveys were due to students changing their conception of learning from equal to personal understanding and development; in other words, moving towards a deeper conception of learning.

Table 3: Section A (Comparison of Students' Conceptions of Learning) of the ASSIST Survey for Group B (virtual) in ASSIST1 and ASSIST2.

\begin{tabular}{|l|l|l|}
\hline Conceptions of Learning for Group A & ASSIST1 & ASSIST2 \\
\hline Personal understanding and development & $44 \%$ & $69 \%$ \\
\hline Equal & $31 \%$ & $6 \%$ \\
\hline Reproducing knowledge & $25 \%$ & $25 \%$ \\
\hline
\end{tabular}

\section{Section B of the ASSIST - Approaches to learning}

Section B of the ASSIST identifies students' individual approaches to learning. Table 4 shows the results of Section B of both ASSIST surveys for Group A (optical). At the beginning of semester (ASSIST1), $42 \%$ of students identified a deep approach to learning and $47 \%$ identified strategic. Only a small percentage (11\%) identified a surface approach to their learning. At the end of semester (ASSIST2), the number of students identifying a deep approach to learning had dropped to $11 \%$ while there were substantial increases in both strategic $(58 \%)$ and surface $(31 \%)$. These results indicate that almost one third of the students $(31 \%)$ changed their learning approach from deep to either a strategic or surface. There was an $11 \%$ increase in the strategic learning approach and a $20 \%$ increase in the surface approach. 
Informing Students Using Virtual Microscopes

Table 4: Section B (Approaches to Learning) of the ASSIST surveys for Group A (optical).

\begin{tabular}{|l|l|l|l|l|}
\hline \multirow{2}{*}{ Survey } & \multicolumn{3}{|c|}{ Learning Approach } & \multirow{2}{*}{ Total } \\
\cline { 2 - 4 } & Deep & Strategic & Surface & $100 \%$ \\
\hline ASSIST1 & $42 \%$ & $47 \%$ & $11 \%$ & $100 \%$ \\
\hline ASSIST2 & $11 \%$ & $58 \%$ & $31 \%$ & \multirow{2}{*}{} \\
\hline
\end{tabular}

Table 5 shows the results of Section B of both ASSIST surveys for Group B (virtual). At the beginning of semester (ASSIST1), approximately one-third of students (31\%) identified a deep approach to learning and half of the students (50\%) identified strategic. A smaller percentage (19\%) identified a surface approach to their learning. At the end of semester (ASSIST2), the number of students identifying a deep approach to learning had dropped to $19 \%$ and there was an increase of $12 \%$ in strategic. The number of students identifying surface remained the same $(19 \%)$.

Table 5: Section B (Approaches to Learning) of the ASSIST surveys for Group B (virtual).

\begin{tabular}{|l|c|c|c|c|}
\hline \multirow{2}{*}{ Survey } & \multicolumn{3}{|c|}{ Learning Approach } & \multirow{2}{*}{ Total } \\
\cline { 2 - 4 } & Deep & Strategic & Surface & $100 \%$ \\
\hline ASSIST1 & $31 \%$ & $50 \%$ & $19 \%$ & $100 \%$ \\
\hline ASSIST2 & $19 \%$ & $62 \%$ & $19 \%$ & \\
\hline
\end{tabular}

Table 6 indicates the changes to approaches to learning over the semester by each group.

Table 6: Changes to learning approaches over semester

\begin{tabular}{|l|c|c|c|c|}
\hline \multirow{2}{*}{ Group } & \multicolumn{3}{|c|}{ Learning Approach } & \multirow{2}{*}{ Total } \\
\cline { 2 - 4 } & Deep & Strategic & Surface & $63 \%$ \\
\hline Group A & $-31 \%$ & $+11 \%$ & $+20 \%$ & $37 \%$ \\
\hline Group B & $-12 \%$ & $+12 \%$ & $0 \%$ & $3 \%$ \\
\hline
\end{tabular}

\section{Section C of the ASSIST - Preferences for courses and teaching}

The third section of the ASSIST survey, Section C, determines students' preferences for different types of courses and teaching. Table 7 shows the results of Section C of both ASSIST surveys for Group A (optical). At the beginning of semester (ASSIST1), approximately one-quarter of students $(26 \%)$ displayed a preference relating to a deep approach (supporting understanding) and more than two-thirds of the students $(69 \%)$ showed a preference relating to a surface approach (transmitting information). The remaining 5\% showed equal preferences.

At the end of semester (ASSIST2), the number of students displaying a preference for a deep approach remained the same (26\%) but there was a drop to approximately one-third of students $(32 \%)$ displaying a preference for a surface approach. There was a large increase in those showing equal preferences.

Table 7: Section C (Preference for Different Types of Course and Teaching) of the ASSIST Surveys for Group A (optical).

\begin{tabular}{|l|c|c|c|c|}
\hline Survey & $\begin{array}{c}\text { Supporting Un- } \\
\text { derstanding } \\
\text { (related to } a \\
\text { deep approach) }\end{array}$ & $\begin{array}{c}\text { Transmitting } \\
\text { Information } \\
\text { (related to } a \\
\text { surface approach) }\end{array}$ & Equal Score & Total \\
\hline ASSIST1 & $26 \%$ & $69 \%$ & $5 \%$ & $100 \%$ \\
\hline ASSIST2 & $26 \%$ & $32 \%$ & $42 \%$ & $100 \%$ \\
\hline
\end{tabular}


Table 8 shows the results of Section C of both ASSIST surveys for Group B (virtual). At the beginning of semester (ASSIST1), approximately one-fifth of students (19\%) displayed a preference for supporting understanding (a deep approach) with four-fifths of students (81\%) showing a preference for transmitting information (a surface approach). At the end of semester (ASSIST2), the number of students identifying a deep approach to learning had increased to $69 \%$ and there was a decrease to $25 \%$ for a surface approach. The remainder of students $(6 \%)$ showed equal preference.

Table 8: Section C (Preference for Different Types of Course and Teaching) of the ASSIST Surveys for Group B (virtual).

\begin{tabular}{|l|c|c|c|c|}
\hline Survey & $\begin{array}{c}\text { Supporting Un- } \\
\text { derstanding } \\
\text { (related to } a \\
\text { deep approach) }\end{array}$ & $\begin{array}{c}\text { Transmitting } \\
\text { Information } \\
\text { (related to a } \\
\text { surface approach) }\end{array}$ & Equal Score & Total \\
\hline ASSIST1 & $19 \%$ & $81 \%$ & $0 \%$ & $100 \%$ \\
\hline ASSIST2 & $69 \%$ & $25 \%$ & $6 \%$ & $100 \%$ \\
\hline
\end{tabular}

The final item of the survey asked students to rate themselves on how well they thought they had been doing in their assessed work so far, on a scale of 1 (very badly) to 9 (very well). Students were directed to ignore this question in ASSIST1 as they had not completed any assessed work at this point in time. In ASSIST2, students answered the question when they were in the last teaching week. Table 9 shows that in Group A (optical), $79 \%$ of students rated themselves with a 5 (about average) to 9 (very well) and the remaining 21\% rated themselves as 4 to 1 (rather badly). In Group B (virtual), $69 \%$ of students rated themselves as average or above and $31 \%$ rated themselves less than average.

Table 9: Students' assessment of how well they had been doing in their assessed work (ASSIST2) for Group A (optical) and Group B (virtual).

\begin{tabular}{|l|c|c|c|c|c|c|c|c|c|}
\hline Group & $\begin{array}{c}9 \\
\text { Very } \\
\text { well }\end{array}$ & 8 & $\begin{array}{c}7 \\
\text { Quite } \\
\text { well }\end{array}$ & 6 & $\begin{array}{c}5 \\
\text { About } \\
\text { average }\end{array}$ & 4 & $\begin{array}{c}3 \\
\text { Not so } \\
\text { well }\end{array}$ & 2 & $\begin{array}{c}1 \\
\text { Rather } \\
\text { badly }\end{array}$ \\
\hline Group A & $0 \%$ & $0 \%$ & $42 \%$ & $11 \%$ & $26 \%$ & $16 \%$ & $0 \%$ & $5 \%$ & $0 \%$ \\
\hline Group B & $0 \%$ & $6 \%$ & $25 \%$ & $25 \%$ & $13 \%$ & $13 \%$ & $6 \%$ & $0 \%$ & $12 \%$ \\
\hline
\end{tabular}

\section{Log books}

Students filled in log books to record the time they spent studying (in hours), which included lectures, laboratories and self-study for histology and pathology. The total time spent studying by students in Group A (optical) varied from 37 to 142 hours. The total time spent studying by students in Group B (virtual) varied from 56 to 139 hours. Table 10 shows the relationship between the amounts of time spent studying by students in both Groups A (optical) and B (virtual) and their final mark. 
Table 10: Relationship between time spent studying and final grade for Group A (optical) and Group B (virtual) students

\begin{tabular}{|c|c|c|}
\hline Code & Total Time & Final Mark \\
\hline 30 & 58 & 82 \\
\hline 37 & 118 & 80 \\
\hline 40 & 110 & 80 \\
\hline 15 & 71 & 75 \\
\hline 10 & 55 & 75 \\
\hline 2 & 137 & 74 \\
\hline 33 & 85 & 74 \\
\hline 1 & 124 & 74 \\
\hline 39 & 51 & 73 \\
\hline 4 & 37 & 72 \\
\hline 28 & 142 & 72 \\
\hline 23 & 108 & 68 \\
\hline 14 & 87 & 66 \\
\hline 31 & 66 & 62 \\
\hline 8 & 111 & 61 \\
\hline 34 & 52 & 60 \\
\hline 9 & 86 & 58 \\
\hline 3 & 59 & 57 \\
\hline 18 & 74 & 55 \\
\hline Average & 86 & 69 \\
\hline & \\
\hline
\end{tabular}

Group A (optical)

\begin{tabular}{|c|c|c|}
\hline Code & Total Time & Final Mark \\
\hline 26 & 69 & 90 \\
\hline 13 & 93 & 80 \\
\hline 38 & 56 & 80 \\
\hline 16 & 87 & 75 \\
\hline 32 & 56 & 73 \\
\hline 22 & 56 & 71 \\
\hline 24 & 93 & 70 \\
\hline 12 & 104 & 70 \\
\hline 42 & 111 & 68 \\
\hline 6 & 119 & 68 \\
\hline 21 & 83 & 67 \\
\hline 36 & 88 & 67 \\
\hline 43 & 127 & 66 \\
\hline 5 & 99 & 63 \\
\hline 41 & 137 & 61 \\
\hline 29 & 139 & 60 \\
\hline Average & 95 & 71 \\
\hline
\end{tabular}

The average time that Group A (optical) spent studying was 86 hours and the average mark was 69. The average time that Group B (virtual) spent studying was 95 hours and the average mark was 71 .

\section{Discussion}

This paper described an exploratory study to identify students' approaches to studying histology and pathology, and the impact of virtual microscopes into the learning environment. The two groups - one group using optical microscopes and the other group using virtual microscopes - did exhibit differing results.

Section A of the ASSIST survey measures students' conceptions about learning. Students' conceptions about learning show whether they see learning as being about personal understanding and development (related more to a deep approach) or whether they see learning as reproducing knowledge (related more to a surface approach). There was a decrease in the optical group and an increase in the virtual group in personal understanding between the beginning and end of semester. The change therefore suggests that the virtual group became more deeply involved with the course material.

Section B of the ASSIST survey measures students' individual approaches to learning. In this section, the results indicated that there was a decrease in deep learning for both groups, with some of the optical group changing to both strategic and surface and some of the virtual group changing 
to strategic. One would expect that, as pressures mount with increased workload throughout the semester, students would discover strategies for minimising their work. However, it was interesting that some of the students in the optical group changed to a surface approach but those in the virtual group changed only to strategic.

Section C of the ASSIST survey determines students' preferences for different types of courses and teaching. The two preferences are supporting understanding (related to a deep approach) and transmitting information (related to a surface approach). As in Section A, the two groups demonstrated different trends. Students in the optical group moved from a preference for a surface approach for teaching to an equivocal preference, i.e. no clear preference for either deep or surface. A number of students in the virtual group changed from a preference for a surface approach for teaching to a preference for a deep approach.

At the end of the semester, students were asked to rate themselves on how well they thought they had been doing in their assessed work. Overall, the optical group's perception of their progress was more favourable than the virtual group. One explanation for this variance could be related to the greater amount of time, on average, that the virtual group spent studying, even though this group moved towards a more strategic approach.

In addition to the ASSIST surveys, students kept a record of the amount of time they spent on their work throughout the semester. One would expect a relationship between the amount of time and their final mark. However, there was no significant correlation for the optical group and a negative correlation for the virtual group. In other words, the more time that students in the virtual group studied, the less likely they were to do well. One possible explanation for this result could be the novelty of the technology. The time that the virtual group recorded could have been in exploring the new techniques of virtual microscopes. On the other hand, as more students in the virtual group changed to a strategic approach to studying, perhaps this group was engaging more in the wider discipline as they experimented with the novel technology. This is an interesting finding from the study which needs further investigation and one which appears prima facie to support Russell's claim that " $t$ t]here is nothing inherent in the technology that elicits improvements in learning".

It must be stressed that the findings in this paper should be regarded as exploratory as the numbers in each group (19 in Group A; 16 in Group B) were small. Richer data is required to investigate further the reasons for the changes in students' approaches over the semester. This data will be gathered by individual interviews and/or focus groups with students. In addition, a further study with larger group numbers is planned in 2007.

The results in this exploratory study do show a differential trend between the two groups, which is certainly worth pursuing. The trend appears to be that the virtual group moved more towards a strategic approach to learning but identified a preference for a deep approach to teaching.

\section{References}

Aperio Technologies Inc. (2006). http://www.aperio.com. Accessed 30 January.

Bates, A. W., \& Poole, G. (2003). Effective teaching with technology in higher education: Foundations for success: Jossey-Bass.

Biggs, J. (1987). Student approaches to learning and studying. Hawthorne, Australia: Council for Educational Research.

Biggs, J. (2003). Teaching for quality learning at university (2nd ed.). Berkshire, UK: Open University Press.

Coffield, F., Moseley, D., Hall, E., \& Ecclestone, K. (2004). Learning styles and pedagogy in post-16 learning: A systematic and critical review. Wiltshire, UK: The Learning and Skills Research Centre. 
Informing Students Using Virtual Microscopes

Entwistle, N. (2000). Approaches and study skills inventory for students (ASSIST). Accessed 25 August 2005, from http://www.tla.ed.ac.uk/etl/questionnaires/ASSIST.pdf

Entwistle, N., Tait, H., \& McCune, V. (2000). Patterns of response to an approach to studying inventory across contrasting groups and contexts. European Journal of the Psychology of Education, 15, 33-48.

Garrison, D. R., \& Anderson, T. (2003). E-learning in the 21st century: A framework for research and practice. London: Routledge Falmer.

Harris, T., Leaven, T., Heidger, P., Kreiter, C., Duncan, J., \& Dick, F. (2001). Comparison of a virtual microscope laboratory to a regular microscope laboratory for teaching histology. The Anatomical Record (New Anat.), 265, 10-14.

McCune, V., \& Entwistle, N. J. (2000). The deep approach to learning: analytic abstraction and idiosyncratic development. Paper presented at the Innovations in Higher Education Conference, Helsinki, Finland.

McCune, V., \& Hounsell, D. (2005). The development of students' ways of thinking and practising in three final-year biology courses. Higher Education, 49, 255-289.

Russell, T. L. (1999). The no significant difference phenomenon. Raleigh, NC: North Carolina State University.

Ryan, M. T., Irwin, J. A., Bannon, F. J., Mulholland, C. W., \& Baird, A. W. (2004). Observations of veterinary medicine students' approaches to study in pre-clinical years. European Veterinary Education: Structuring Future Development, 31(3), 242-254.

Vermunt, J. D. (1988). The regulation of constructive learning processes. British Journal of Educational Psychology, 68, 149-171.

\section{Biographies}

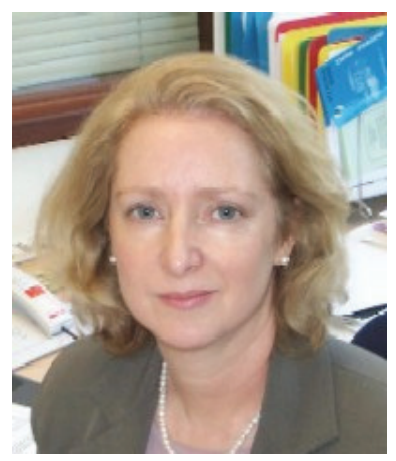

Diana Jonas-Dwyer is a Senior Lecturer in Medical Education at the University of Western Australia where she provides advice and support to staff on the educational use of technologies in their teaching. She is a Member of Australasian Society for Computers in Learning in Tertiary Education (ASCILITE).

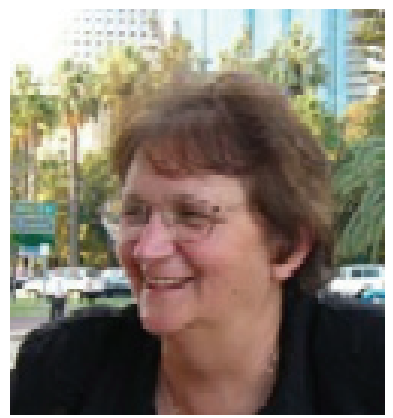

Fay Sudweeks is a Senior Lecturer in Information Systems at Murdoch University. She has a Bachelor of Arts (Psychology and Sociology), Master of Cognitive Science and Doctor of Philosophy (Communication Studies), and is a Member of the Australian Computer Society. She is on the editorial board of the Journal of Computer-Mediated Communication, New Media and Society, Human Communication Research, and International Journal of e-Learning. With Professor Charles Ess, she has co-chaired five international and interdisciplinary conferences on Cultural Attitudes towards Technology and Communication. 